\title{
Pretraining NMDA Receptor Blockade in the Basolateral Complex, but Not the Central Nucleus, of the Amygdala Prevents Savings of Conditional Fear
}

\author{
Ki A. Goosens and Stephen Maren \\ University of Michigan
}

\begin{abstract}
The acquisition of conditional freezing is abolished by $N$-methyl-D-aspartate (NMDA) receptor antagonism in the basolateral complex of the amygdala (BLA) during fear conditioning, suggesting that memory formation is prevented. The present study examined whether there is residual memory, or "savings," for fear conditioning in rats trained under amygdaloid NMDA receptor blockade. Rats infused with D,L-2-amino-5-phosphonovalerate (APV) into the BLA or central nucleus of the amygdala (CEA) during fear conditioning did not acquire either auditory or contextual fear conditioning. However, savings of conditional fear was exhibited by rats infused with APV into the CEA but not the BLA. These results suggest that both the BLA and CEA play a critical role in the acquisition of conditional fear but that the BLA is able to process and retain some aspects of aversive memories in the absence of the CEA.
\end{abstract}

Pavlovian fear conditioning in rats is a model system used to study the neural mechanisms underlying emotional learning and memory. In a typical experiment, naive rats are placed in a chamber (the conditioning "context") and presented with a conditional stimulus (CS), such as a tone, followed by an aversive footshock unconditioned stimulus (US). After several pairings, the CS comes to elicit many conditional responses, including increased heart rate, blood pressure, and acoustic startle and somatomotor immobility (i.e., freezing). These conditional responses may be measured in later extinction sessions as an index of memory for previous training.

Considerable evidence points to the nuclei of the amygdala as being particularly important for fear conditioning (Davis, 1992; Fendt \& Fanselow, 1999; LeDoux, 2000; Maren, 2001b). Lesions of either the basolateral complex (BLA; consisting of the lateral [LA], basolateral [BL], and basomedial [BM] nuclei) or the central nucleus (CEA) produce deficits in the acquisition and expression of conditional fear (Campeau \& Davis, 1995; Goosens \& Maren, 2001; Y. Lee, Walker, \& Davis, 1996; Maren, 1998, 1999b; Maren, Aharonov, \& Fanselow, 1996; Sananes \& Davis, 1992). Moreover, fear conditioning induces associative neuronal activity in both the CEA (Applegate, Frysinger, Kapp, \& Gallagher, 1982; Pascoe \& Kapp, 1985) and the BLA (Maren, 2000; Maren,

Ki A. Goosens, Department of Psychology, University of Michigan; Stephen Maren, Department of Psychology and Neuroscience Program, University of Michigan.

Ki A. Goosens is now at the Department of Biological Sciences, Stanford University.

This research was supported by National Institute of Mental Health Grant R29MH57865 to Stephen Maren. Ki A. Goosens was a Howard Hughes predoctoral fellow. We would like to thank Heather Tracy for technical assistance.

Correspondence concerning this article should be addressed to Stephen Maren, Department of Psychology, University of Michigan, 525 East University Avenue, Ann Arbor, Michigan 48109-1109. E-mail: maren@umich.edu
Poremba, \& Gabriel, 1991; Quirk, Armony, \& LeDoux, 1997; Quirk, Repa, \& LeDoux, 1995; Repa, Apergis, Desrochers, Zhou, \& LeDoux, 2001).

The amygdala also appears to be a site of convergence for information about both the CS and the US. LA neurons receive input from neurons in the medial geniculate nucleus of the thalamus (MGN), thought to be the primary relay of auditory information to the amygdala (Quirk et al., 1995, 1997). Neurons in the auditory cortex, which are also capable of transmitting sensory information to the amygdala (Romanski \& LeDoux, 1992), project to the same amygdaloid nuclei as do MGN neurons (LeDoux Farb, \& Romanski, 1991). In contrast, contextual cues are processed in the hippocampus (Kim \& Fanselow, 1992; Maren, Aharonov, \& Fanselow, 1997; Phillips \& LeDoux, 1992), and hippocampal afferents to the amygdala synapse primarily on neurons of BL and BM (Canteras \& Swanson, 1992; Maren \& Fanselow, 1995). The CEA receives direct inputs from BL and BM. It projects to the brainstem areas controlling the expression of fear responses (LeDoux, Iwata, Cicchetti, \& Reis, 1988), including the ventral periaqueductal gray, which generates freezing behavior (De Oca, DeCola, Maren, \& Fanselow, 1998; Kim, Rison, \& Fanselow, 1993). This anatomical arrangement of connections has led to the idea that the BLA may be critical in forming the CS-US association during conditioning, whereas the CEA serves to translate this association to an appropriate motor response in brainstem structures such as the ventral periaqueductal gray (e.g., Maren \& Fanselow, 1996). That is, the BLA is often considered a "learning" structure, whereas its efferents are thought to be "performance" structures.

There is an abundance of evidence indicating that the BLA makes essential contributions to the associative learning underlying Pavlovian fear conditioning (Fanselow \& LeDoux, 1999; Maren, 1999a). For example, blockade of $N$-methyl-D-aspartate (NMDA) receptors by intra-amygdala infusion of D,L-2-amino-5phosphonovalerate (APV; a selective NMDA receptor antagonist) has been shown to severely attenuate the acquisition (Campeau, 
Miserendino, \& Davis, 1992; Fanselow \& Kim, 1994; Gewirtz \& Davis, 1997; Maren, Aharonov, Stote, \& Fanselow, 1996; Miserendino, Sananes, Melia, \& Davis, 1990) and, in some cases, the expression (Fendt, 2001; H. J. Lee, Choi, Brown, \& Kim, 2001; H. Lee \& Kim, 1998; Maren, Aharonov, et al., 1996) of conditioned fear. NMDA-receptor-dependent long-term potentiation (LTP), a cellular model of learning and memory, can be induced in the BLA through stimulation of likely CS pathways, including the hippocampal formation (Maren \& Fanselow, 1995) and the MGN (Clugnet \& LeDoux, 1990; Rogan \& LeDoux, 1995). Moreover, fear conditioning induces LTP-like increases in BLA field potentials both in vitro (McKernan \& Shinnick-Gallagher, 1997) and in vivo (Rogan, Staübli, \& LeDoux, 1997).

Collectively, these experiments suggest that NMDA receptor blockade in the BLA is sufficient to prevent associative learning during fear conditioning. However, it has been suggested that structures other than the amygdala may be responsible for encoding CS-US associations during fear conditioning (Cahill, Weinberger, Roozendaal, \& McGaugh, 1999; Weinberger, Javid, \& Lepan, 1993). For example, in the case of auditory fear conditioning, the MGN displays associative single-unit activity during fear learning (Edeline \& Weinberger, 1992; Lennartz \& Weinberger, 1992; McEchron, McCabe, Green, Llabre, \& Schneiderman, 1995). Furthermore, the MGN exhibits LTP (Gerren \& Weinberger, 1983), and fear conditioning induces synaptic plasticity in the MGN (McEchron et al., 1996). It is possible that amygdala afferents such as the MGN, or perhaps even cortical areas (Cahill et al., 1999), are the critical loci of associative learning during Pavlovian fear conditioning. These structures would then passively transmit this plasticity to the amygdala, which could subsequently modulate conditional responding (but see Maren, Yap, \& Goosens, 2001, and Poremba \& Gabriel, 2001). By this view, the absence of conditional fear responses in rats trained under amygdaloid NMDA receptor blockade may be attributed to difficulty in retrieving the fear memory during extinction testing. Alternatively, rats trained under amygdaloid NMDA receptor blockade may acquire a subthreshold CS-US association that is insufficient to elicit conditional fear. In either of these scenarios, additional training in a drug-free state might reinstate the fear memories in rats trained under NMDA receptor blockade. Presentation of the US might serve as a reminder to facilitate retrieval of the conditioning memory, or additional training might summate with the subthreshold trace to yield a conditional response.

To address these issues, we performed two experiments in which APV was infused into either the BLA or CEA immediately before fear conditioning, and we later assessed behavioral savings of the initial conditioning session during subsequent retraining. Savings is learning that may not be manifest during an initial testing session but may be expressed as facilitated reacquisition relative to naive controls (see Clark \& Lavond, 1993). We found that pretraining infusion of APV into the BLA or CEA prevented the acquisition of conditional fear. In addition, pretraining infusion of APV into the BLA prevented savings of both contextual and auditory fear. Pretraining infusion of APV into the CEA yielded savings of both contextual and auditory fear. The effects of pretraining NMDA receptor blockade in the CEA on acquisition and savings of conditional fear could not be accounted for by diffusion of the drug into nearby structures such as the caudate-putamen $(\mathrm{CPu})$. Collectively, these experiments suggest a novel role for the
CEA in the acquisition of conditional fear and strengthen the claims that amygdaloid NMDA receptor activation is essential for encoding CS-US associations during Pavlovian fear conditioning.

\section{General Method}

\section{Subjects}

The subjects were 235 adult male Long-Evans rats (200-224 g) obtained from a commercial supplier (Harlan Sprague-Dawley, Indianapolis, IN). After arrival, the rats were individually housed in standard Plexiglas hanging cages on a 14:10-hr light-dark cycle (lights on at 7 a.m.) and provided free access to food and tap water. After housing, rats were handled for $30 \mathrm{~s}$ per day for 5 days to acclimate them to the experimenters. All procedures were approved by the University Committee on Use and Care of Animals at the University of Michigan.

\section{Surgery}

One week before behavioral testing, rats were implanted with bilateral guide cannulas (26 gauge, $15 \mathrm{~mm}$; Plastics One, Roanoke, VA) aimed at the BLA (2.3 mm posterior to bregma, $5.0 \mathrm{~mm}$ lateral to the midline, 6.3 $\mathrm{mm}$ ventral to dura), CEA (2.0 $\mathrm{mm}$ posterior to bregma, $4.0 \mathrm{~mm}$ lateral to the midline, $5.7 \mathrm{~mm}$ ventral to dura), or $\mathrm{CPu}(2.0 \mathrm{~mm}$ posterior to bregma, $4.0 \mathrm{~mm}$ lateral to the midline, $3.7 \mathrm{~mm}$ ventral to dura). Rats were anesthetized with sodium pentobarbital $(65 \mathrm{mg} / \mathrm{kg}$ ip) and were administered atropine methyl nitrate $(0.04 \mathrm{mg} / \mathrm{kg}$ ip) to prevent obstruction of the airway. After mounting in a stereotaxic apparatus (Kopf Instruments, Tujunga, CA), the scalp was incised and retracted, and lambda and bregma were placed in the same horizontal plane. Small burr holes (1 mm diameter) were drilled for placement of the guide cannulas and three small jeweler's screws. The guide cannulas were lowered and dental acrylic was applied to the skull to hold the cannulas in place. After surgery, dummy cannulas (33 gauge, $16 \mathrm{~mm}$; Plastics One, Roanoke, VA) were inserted into the guide cannulas, and the rats were returned to their home cages. The dummy cannulas were replaced every other day during the week of recovery.

\section{Behavioral Apparatus}

All training and testing occurred in eight identical observation chambers $(30 \times 24 \times 21 \mathrm{~cm}$; MED Associates, Burlington, VT) located in soundattenuating cabinets in an isolated room. The chambers were constructed of aluminum (two side walls) and Plexiglas (rear wall, ceiling, and hinged front door). The floor of each chamber consisted of 19 stainless steel rods (4 mm diameter) spaced $1.5 \mathrm{~cm}$ apart (center to center). The rods were wired to a shock source and solid-state grid scrambler (MED Associates, Burlington, VT) for the delivery of footshock USs. A speaker used in delivering acoustic stimuli was mounted to a grating on one wall of each chamber.

Each conditioning chamber was situated on a load-cell platform that recorded chamber displacement in response to each rat's motor activity. The output of each chamber's load cell was amplified (vernier knob $=8$ ) at a level previously determined to optimize detection of freezing behavior (see Maren, 1998). The load-cell amplifier output from each chamber was digitized at $5 \mathrm{~Hz}$ (yielding 300 observations per minute per rat) and acquired on-line through the use of Threshold Activity software (MED Associates, Burlington, VT). The raw load-cell output was used to quantify activity. Freezing was quantified by calculating the number of observations below a freezing threshold (load-cell activity level of 5 or below; see Maren, 1998). Freezing was scored only if a rat was immobile for $1 \mathrm{~s}$ or longer; thus, freezing was scored only for five or more contiguous observations. For each session, freezing observations were converted to a percentage of total observations. 
Two experimental contexts were used. For Context A, chambers were cleaned with a 5\% ammonium hydroxide solution, and stainless steel pans with a thin layer of the same solution were situated under the grid floors before rats were placed in the chambers. Illumination was provided by both the room lights and a small stimulus light $(15 \mathrm{~W})$ in each chamber, and background noise ( $65 \mathrm{~dB}$, A scale) was supplied by ventilation fans in each chest. For Context B, 1\% acetic acid was used to clean the chambers and placed in the pans beneath the grid floors. Illumination was provided solely by a red light $(30 \mathrm{~W})$ located in the room, and ventilation fans were turned off.

\section{Drug Infusion}

Pairs of rats were transported to an isolated room in plastic buckets containing a thin layer of pine shavings. Dummy cannulas were removed from each rat, and injection cannulas extending $1 \mathrm{~mm}$ past the end of the guide cannulas (Plastics One, Roanoke, VA) were inserted. The injection cannulas were connected to a $10 \mu$ l Hamilton syringe with polyethylene tubing (PE-20; Fisher, Pittsburgh, PA) and mounted in an infusion pump (Harvard Apparatus, South Natick, MA). Rats were infused either with vehicle (VEH; $0.1 \mathrm{M}$ phosphate-buffered saline, $\mathrm{pH}$ 7.4) or APV (10 $\mu \mathrm{g} / \mu \mathrm{l}$; Sigma Chemical, St. Louis, MO). The infusion rate was $0.1 \mu \mathrm{l} / \mathrm{min}$. During this time, rats were permitted to explore freely within the buckets; however, they were distracted when attempting to groom because grooming often dislodged the injection cannulas. After the pumps were turned off, 1 min was allowed for diffusion before the injectors were removed. Rats were immediately transported to the conditioning chambers.

\section{Histology}

Histological verification of cannula placement was performed after behavioral testing. Rats were perfused across the heart with $0.9 \%$ saline followed by $10 \%$ Formalin. Brains were removed from the skull and placed in $10 \%$ Formalin for 2 days and $10 \%$ Formalin/30\% sucrose until sectioning. Coronal sections (40 $\mu \mathrm{m}$ thick, taken every $120 \mu \mathrm{m})$ were cut on a cryostat $\left(-18^{\circ} \mathrm{C}\right)$ and wet mounted on glass microscope slides with $95 \%$ ethanol. After drying, sections were stained with $0.25 \%$ thionin to allow visualization of cell bodies. Cannula placements were reconstructed on stereotaxic atlas templates (Swanson, 1999). Rats were excluded from statistical analyses if the cannulas were not both located in a single target structure (BLA, CEA, or $\mathrm{CPu}$ )

\section{Data Analysis}

Freezing was calculated as a percentage of total observations, a probability estimate amenable to analysis with parametric statistics. Probability estimates of freezing were assessed through analysis of variance (ANOVA). Post hoc comparisons in the form of Fisher's protected least significant difference tests were performed on the freezing averages after a significant omnibus $F$ ratio. All data shown in the figures are represented as means plus or minus standard errors of the means.

\section{Experiment 1}

The first experiment examined whether NMDA receptor blockade in the BLA or CEA during auditory fear conditioning would affect the acquisition and savings of auditory fear memories. Rats were fear conditioned after intra-amygdala infusion of either APV or VEH and later administered additional infusion-free conditioning. Savings was measured relative to a VEH-infused group that did not receive fear conditioning on the first day of training.

\section{Method}

The experiment was conducted in two phases (see Figure 1A). The first phase consisted of a single day of massed-trial auditory fear conditioning administered immediately after infusion of APV or VEH. The second phase (Test Days 1-4) consisted of 4 days of one-trial-per-day gradual reacquisition with no infusion before any session. Each test day was separated by several days of exposure to the training context to extinguish fear of this context before each CS test trial. Only when the rats had extinguished contextual fear were they administered extinction testing and retraining for auditory fear. Rats $(n=53)$ were assigned to one of three groups describing treatment on the day of massed training: AT+/APV, $\mathrm{AT}-/ \mathrm{VEH}$, or AT+/VEH. These groups differed in the type of infusion received before massed-trial fear conditioning (APV or VEH) and the presence ("+") or absence ("-") of shock during this session. All training and testing were performed in the A context. One rat died postoperatively, and 7 rats were excluded from the analyses because of improper placement of guide cannulas. This yielded the following groups: AT+/APV-BLA $(n=8), \mathrm{AT}+/ \mathrm{VEH}-\mathrm{BLA}(n=5), \mathrm{AT}-/ \mathrm{VEH}-\mathrm{BLA}(n=4), \mathrm{AT}+/ \mathrm{APV}-$ CEA $(n=16)$, AT-/VEH-CEA $(n=6)$, and AT+/VEH-CEA $(n=6)$, Savings in the AT+/APV groups was assessed by comparing the rate of reacquisition on Test Days 1 through 4 (indicated by freezing behavior during tone presentation on each test day) with the rate of reacquisition in rats receiving VEH infusion before the massed training (the AT-/VEH and $\mathrm{AT}+/ \mathrm{VEH}$ groups). The rate of reacquisition among animals in these groups during infusion-free reacquisition days was a measure of the influence (or savings) of either context exposure in the absence of shock (AT-/VEH) or context-US association (AT+/VEH).

The day before massed-trial training, rats were preexposed to the infusion procedure. Rats were transported in squads of 4 to the infusion room. On arrival, the dummy cannulas were removed, and mock injection cannulas that did not extend into the target brain structure were placed in the guide cannulas. The infusion pumps were turned on for $5 \mathrm{~min}$ at a rate of $0.1 \mu \mathrm{l} / \mathrm{min}$ to acclimate the rats to the sound of the pumps; however, the pumps were prevented from making contact with the plungers of the syringes. At the end of the 5-min period, the mock injectors were removed and the rats were transported back to their home cages.

For massed-trial training, the rats were transported in squads of 2 to the infusion room. All infusions were conducted at a rate of $0.1 \mu \mathrm{l} / \mathrm{min}$. Rats with guide cannulas aimed at the BLA received a $0.5 \mu \mathrm{l}$ infusion of APV ( $5 \mu \mathrm{g} / \mathrm{side}$ ) or VEH into each BLA. Rats with guide cannulas aimed at the CEA received a $0.25 \mu \mathrm{l}$ infusion of APV $(2.5 \mu \mathrm{g} / \mathrm{side})$ or VEH into each CEA. A smaller volume and dose of APV was infused into the CEA because the CEA is composed of a smaller volume of brain tissue than the BLA. One minute after the infusion was completed, the injectors were replaced with dummy cannulas, and the rats were immediately placed into the conditioning chambers.

Three minutes after placement in the chambers, rats in the AT+ groups received five tone $(85 \mathrm{~dB}, 10 \mathrm{~s}, 2 \mathrm{kHz})$-footshock $(1 \mathrm{~s}, 1.0 \mathrm{~mA} ; 70-\mathrm{s}$ intershock interval) pairings. One minute after the last footshock, the rats were returned to their home cages. Rats in the AT - group received five tone $(85 \mathrm{~dB}, 10 \mathrm{~s}, 2 \mathrm{kHz})$ presentations $3 \mathrm{~min}$ after being placed in the conditioning chambers; no footshock was delivered. All rats were returned to their home cages no more than 15 min after completion of the infusion. On all subsequent days, all groups received identical retraining and testing. Rats were transported to the conditioning room each day and placed in the conditioning chambers. For several days following each session in which shock was administered, all rats received $40 \mathrm{~min}$ or $60 \mathrm{~min}$ of context extinction testing in which no footshock occurred. Because massed-trial training and subsequent retraining and testing all occurred in the same context, this procedure was necessary to ensure that any freezing observed during the tone presentation on Test Days 1-4 was due to the tone-US association rather than the context-US association. After all rats had extinguished contextual fear, rats were given a tone extinction test and retrained (Test Days 1-4). Thus, on each test day, animals were placed in 

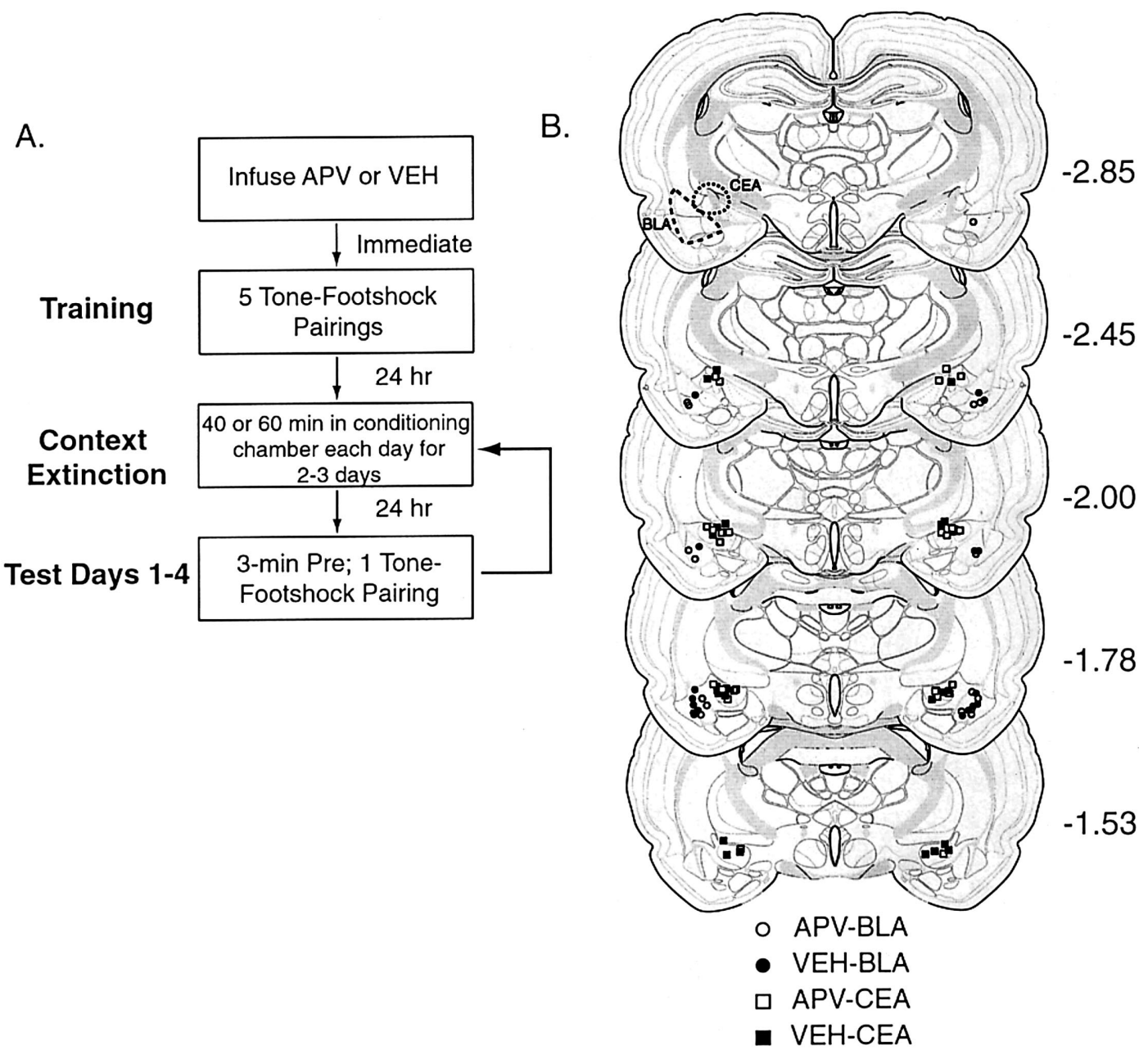

Figure 1. A: Experiment 1 design. Savings of auditory fear was assessed by measuring freezing to a 1-min auditory conditional stimulus on the test days. B: Schematic diagram illustrating injection sites in Experiment 1. Open symbols represent the placement of injector tips in rats infused with D,L-2-amino-5-phosphonovalerate (APV). Solid symbols represent the placement of injector tips in rats infused with vehicle (VEH). Numbers next to coronal sections indicate position in millimeters caudal to bregma. Coronal sections are adapted from Swanson (1999). BLA = basolateral complex of the amygdala; CEA = central nucleus of the amygdala.

the conditioning chambers and, 10 min later, presented with a tone $(1$ $\min , 85 \mathrm{~dB}, 2 \mathrm{kHz})$ that was immediately followed by a footshock $(1 \mathrm{~s}, 1.0$ $\mathrm{mA}$ ). This procedure was repeated (context extinction followed by tone extinction testing and retraining) until the animals exhibited asymptotic freezing levels to the tone CS. Freezing behavior was measured throughout all experimental sessions.

\section{Results and Discussion}

Histology. The injection cannula tip placements for all animals used in analyses are summarized in Figure 1B. Placements were bilaterally symmetric, and there were no differences between groups in the distribution of placements.

Behavior. Figure 2 shows that intra-amygdala infusion of APV into the BLA (Figure 2A) before massed-trial training produced severe deficits in auditory fear conditioning on Test Day 1. This was confirmed in the ANOVA by a significant main effect of group, $F(2,14)=8.37, p<.01$. Planned comparisons verified that rats in the AT+/APV-BLA group exhibited levels of freezing that were significantly lower than those shown by the AT+/VEH-BLA group on Test Day 1. Rats in the AT+/APV-BLA group also did not show significantly different levels of conditional freezing from rats in the AT-/VEH-BLA control group on Test Day 1. In contrast, planned comparisons revealed that rats in the $\mathrm{AT}+/$ VEH-BLA group exhibited significantly higher levels of freezing on Test Day 1 than rats in any other group. Thus, infusion of APV into the BLA before fear conditioning prevented the acquisition of contextual fear conditioning.

To examine the rate of reacquisition of conditional fear, we converted the percentage of freezing exhibited by each rat on each day to a percentage of the maximum level of freezing shown by that rat and calculated the mean for each group across this measure (Figure 2B). There was no difference in the maximum percentage of time spent freezing across the three groups, $F(2,14)=0.09, n s$, validating our use of this measure. It is clear from Figure $2 \mathrm{~B}$ that 
A

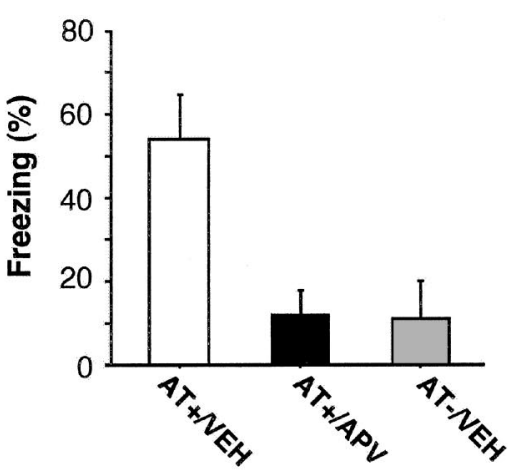

B

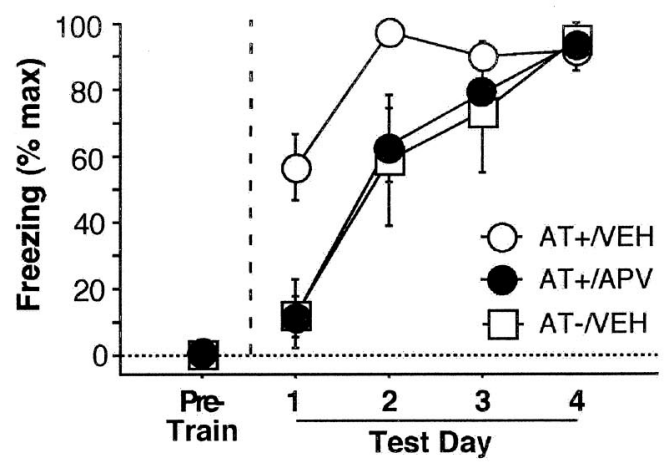

Figure 2. A: Mean $( \pm S E M)$ percentage of time spent freezing on the first test day in rats infused with D,L-2-amino-5-phosphonovalerate (APV) or vehicle (VEH) in the basolateral complex of the amygdala (BLA) before massed-trial auditory fear conditioning in Experiment 1. B: Conditional freezing to an auditory conditional stimulus measured before massed-trial training (Pre-Train) and on test days in rats receiving infusions of APV or VEH into the BLA before massed-trial auditory fear conditioning. For each rat, the maximum (max) percentage of time spent freezing over the 4 test days was identified, and the mean ( \pm SEM) percentage of time spent freezing on each day was expressed relative to this value. Freezing on the training day was measured during the first 10-s tone presentation, whereas freezing was measured on all testing days during a 1-min tone presentation. Freezing on any given test day reflects the cumulative associative value of the tone-unconditional stimulus association from all previous conditioning sessions. All groups received training and testing in the A context (see text). Groups differed in terms of the type of infusion (APV or VEH) received immediately before massed-trial training, as well as the presence $(\mathrm{AT}+)$ or absence $(\mathrm{AT}-)$ of footshock after tone presentation on the training day.

rats infused with APV into the BLA before massed-trial fear conditioning reacquired conditional contextual fear at the same rate as control rats that did not receive massed-trial conditioning (AT-/VEH-BLA group). This was supported in the ANOVA by a significant main effect of group, $F(2,14)=5.76, p<.05$, and a significant Group $\times$ Day interaction, $F(8,56)=2.11, p<.05$. Planned comparisons confirmed that rats in the AT+/APV-BLA group did not exhibit different levels of freezing than rats in the AT-/VEH-BLA group on any test day. Hence, there was no evidence for savings in rats that received intra-BLA infusion of APV during massed-trial auditory fear conditioning.

As shown in Figure 3, infusion of APV into the CEA (Figure $3 \mathrm{~A}$ ) before massed-trial training also produced massive impairments in auditory fear conditioning on Test Day 1. This was confirmed in the ANOVA by a significant main effect of group, $F(2,25)=26.94, p<.0001$. Planned comparisons revealed that rats in the AT+/VEH-BLA group exhibited higher levels of freezing than rats in any other group, and that rats in the AT+/ APV-BLA group exhibited levels of freezing that were not significantly different from rats in the AT-/VEH-BLA control group, on Test Day 1. Thus, infusion of APV into the CEA before fear conditioning prevented the acquisition of contextual fear conditioning.

As for BLA-infused rats, we converted the percentage of freezing exhibited by each rat on each day to a percentage of the maximum level of freezing shown by that rat and calculated the mean for each group across this measure (Figure 3B). We observed no difference in the maximum percentage of time spent freezing across the three groups, $F(2,25)=1.94, n s$. Although rats infused with APV into the CEA before massed- trial fear conditioning did not express conditional fear on Test Day 1, it is clear that additional training yielded savings of auditory fear conditioning in these rats (Figure 3B). Savings was manifested as a greater rate of reacquisition after the first reminder trial. An ANOVA on these data revealed a significant main effect of group, $F(2,25)=15.52, p<.0001$, and a significant Group $\times$ Day interaction, $F(8,100)=4.12, p<$ .001. Planned comparisons showed that rats in the AT+/APV group exhibited significantly more freezing on Test Day 2 than rats in the AT-/VEH group. Thus, whereas infusion of APV into the CEA before massed-trial auditory fear conditioning prevented the acquisition of conditional fear, there was savings for this phase of training when the rats were administered additional footshock reminder trials.

\section{Experiment 2}

The second experiment examined whether NMDA receptor blockade in the BLA or CEA during contextual fear conditioning would affect the acquisition and savings of contextual fear memories (as opposed to the savings of auditory fear memories examined in Experiment 1). Rats were administered contextual fear conditioning after intra-amygdala infusion of either APV or VEH, and they later received additional training. Savings was measured by comparing the rate of reacquisition in these groups relative to a VEH-infused group that was not fear conditioned on the first day. An additional group of rats received the first conditioning session in a different context and served as a nonassociative control for exposure to the footshock US. 
A

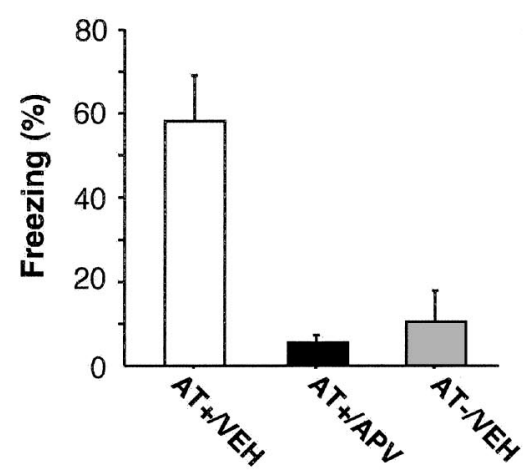

B

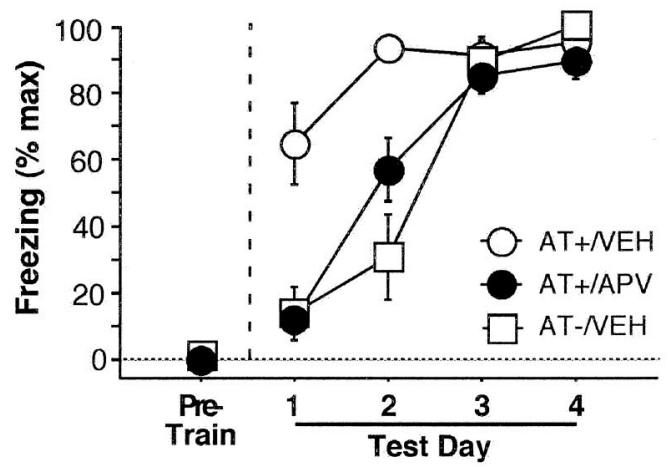

Figure 3. A: Mean $( \pm S E M)$ percentage of time spent freezing on the first test day in rats infused with D,L-2-amino-5-phosphonovalerate (APV) or vehicle (VEH) in the central nucleus of the amygdala (CEA) before massed-trial auditory fear conditioning in Experiment 1. B: Conditional freezing to an auditory conditional stimulus measured before massed-trial training (Pre-Train) and on test days in rats receiving infusions of APV or VEH into the CEA before massed-trial auditory fear conditioning. For each rat, the maximum (max) percentage of time spent freezing over the 4 test days was identified, and the mean ( $\pm S E M$ ) percentage of time spent freezing on each day was expressed relative to this value. Freezing on the training day was measured during the first 10-s tone presentation, whereas freezing was measured on all testing days during a 1-min tone presentation. Freezing on any given test day reflects the cumulative associative value of the tone-unconditional stimulus association from all previous conditioning sessions. All groups received training and testing in the A context. Groups differed in terms of the type of infusion (APV or VEH) received immediately before massed-trial training, as well as the presence $(\mathrm{AT}+)$ or absence $(\mathrm{AT}-)$ of footshock after tone presentation on the training day.

\section{Method}

The experiment was conducted in two phases (see Figure 4A for an illustration of the paradigm). The first phase consisted of a single day of massed-trial contextual fear conditioning that was administered immediately after infusion of APV or VEH. The second phase (Test Days 1-5) consisted of 5 days of one-trial-per-day gradual reacquisition with no infusion before any session. Rats with cannulas in the BLA, CEA, or CPu $(n=182)$ were assigned to one of four groups describing treatment on the day of massed training: $\mathrm{A}+/ \mathrm{APV}, \mathrm{A}-/ \mathrm{VEH}, \mathrm{A}+/ \mathrm{VEH}$, or $\mathrm{B}+/ \mathrm{VEH}$. These groups differed in the type of infusion (APV or VEH) received before the massed-training session, the context in which the massedtraining session occurred (Context A or B), and the presence ("+") or absence ("-") of shock during this session. Twenty-one rats were excluded from the analyses as a result of improper placement of guide cannulas. This yielded the following groups: A+/APV-BLA $(n=25)$, A+/VEH-BLA $(n=17), \mathrm{A}-/ \mathrm{VEH}-\mathrm{BLA}(n=15), \mathrm{B}+/ \mathrm{VEH}-\mathrm{BLA}(n=12), \mathrm{A}+/ \mathrm{APV}-$ CEA $(n=28), \mathrm{A}+$ /VEH-CEA $(n=23), \mathrm{A}-/ \mathrm{VEH}-\mathrm{CEA}(n=21)$, $\mathrm{B}+/ \mathrm{VEH}-\mathrm{CEA}(n=15)$, and A+/APV-CPu $(n=5)$

Savings in the A+/APV groups was assessed by comparing the rate of reacquisition during Test Days 1-5 (indicated by freezing during the first 3 min of each test day) with the rate of reacquisition in rats receiving VEH infusion before the massed training. All groups receiving VEH on the conditioning day served as controls. The rate of reacquisition among animals in these control groups during infusion-free reacquisition days was a measure of the influence of context exposure in the absence of footshock $(\mathrm{A}-/ \mathrm{VEH})$, footshock exposure $(\mathrm{B}+/ \mathrm{VEH})$, or context-US association $(\mathrm{A}+/ \mathrm{VEH})$.

The day before massed-trial training, rats were preexposed to the infusion procedure as described for Experiment 1. On the day of massed-trial training, the rats were transported in squads of 2 to the infusion room. Rats with guide cannulas aimed at the BLA or CEA received infusions as described for Experiment 1. Rats with guide cannulas aimed at the $\mathrm{CPu}$ received a $0.25 \mu \mathrm{l}$ infusion of APV at a rate of $0.1 \mu \mathrm{l} / \mathrm{min}$. This yielded an infusion of $2.5 \mu \mathrm{g}$ of APV per CPu. One minute after the infusion was completed, the injectors were replaced with dummy cannulas, and the rats were immediately placed into the conditioning chambers in either the A or B context.

Three minutes after placement in the chambers, rats in the A+ groups or $\mathrm{B}+$ group received five unsignaled footshocks $(2 \mathrm{~s}, 1.0 \mathrm{~mA} ; 60-\mathrm{s}$ intershock interval). One minute after the last footshock, the rats were returned to their home cages. Rats in the A- group were placed in the chambers for $8 \mathrm{~min}$ before being returned to the vivarium; no footshock was delivered. All rats were returned to their home cages no more than 15 min after completion of the infusion. This ensured that rats infused with APV would be under the influence of the drug throughout the entire massed-training session. During the following 5 days (Test Days 1-5), all groups received identical retraining and testing in Context A. Rats were transported to the conditioning room each day and placed in the conditioning chambers. Three minutes after placement in the chambers, rats received a single unsignaled shock $(1 \mathrm{~s}, 0.6 \mathrm{~mA})$. Rats were returned to their home cages $30 \mathrm{~s}$ after the shock. Pilot experiments demonstrated that naive rats acquire conditional freezing gradually when these training parameters are used, which was essential for comparing rates of reacquisition across groups. Freezing behavior was measured throughout all experimental sessions.

\section{Results and Discussion}

Histology. The injection cannula tip placements for all animals used in analyses are summarized in Figure 4B. Placements were bilaterally symmetric, and there were no differences between groups in the distribution of placements.

Behavior. As shown in Figure 5A, it is apparent that rats infused with VEH into the BLA before massed-trial conditioning exhibited higher levels of freezing behavior after conditioning than before massed-trial conditioning. In contrast, rats that received 

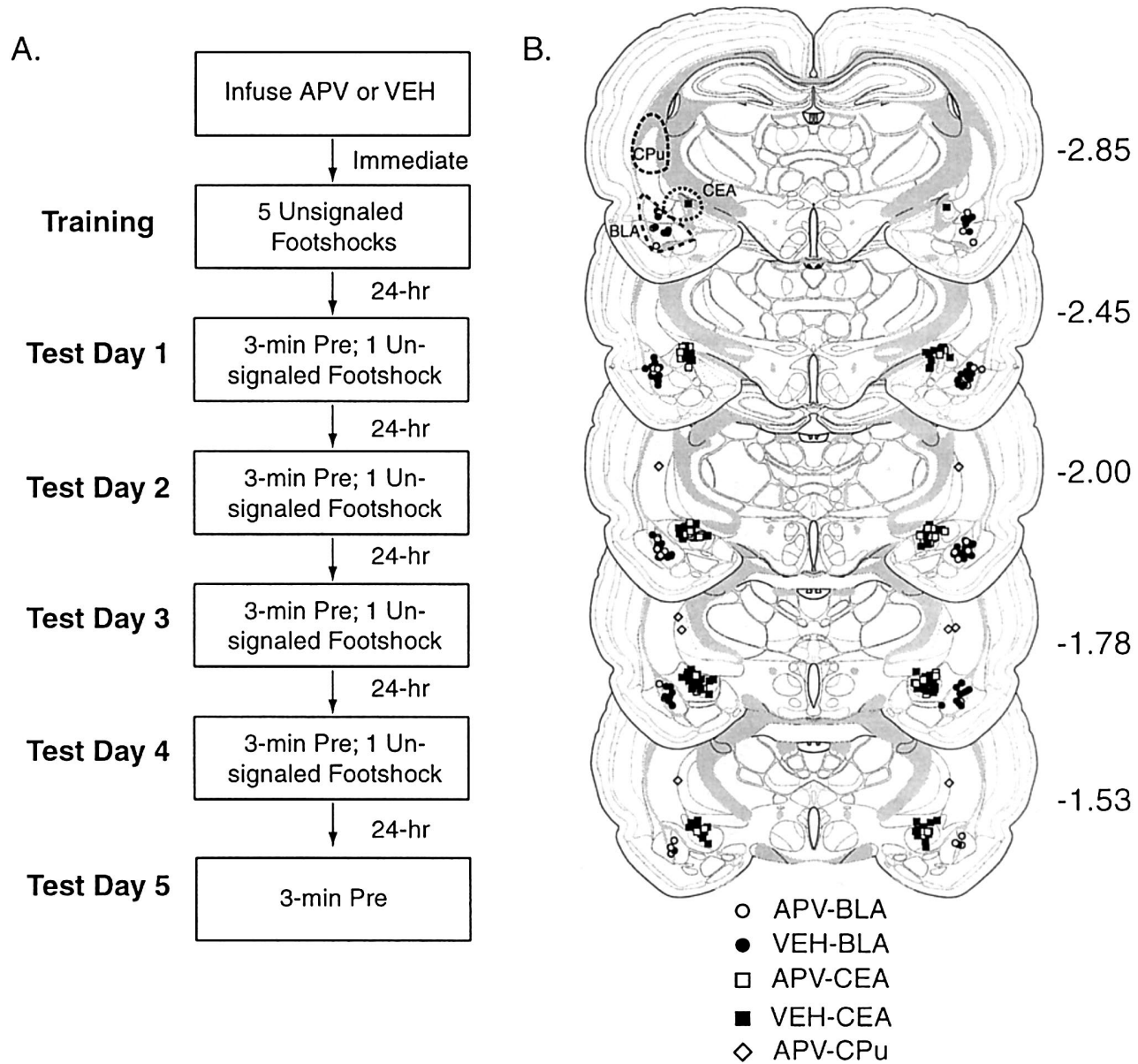

Figure 4. A: Experiment 2 design. Savings of contextual fear was assessed by measuring freezing to contextual cues during the 3-min period before shock delivery on each of the test days. B: Schematic diagram illustrating injection sites in Experiment 2. Open symbols indicate the placement of injector tips in rats infused with D,L-2-amino-5-phosphonovalerate (APV), and solid symbols indicate the placement of injector tips in rats infused with vehicle (VEH). Numbers next to coronal sections reveal position in millimeters caudal to bregma. Coronal sections are adapted from Swanson (1999). BLA = basolateral complex of the amygdala; CEA = central nucleus of the amygdala; $\mathrm{CPu}=$ caudate-putamen.

intra-amygdala infusions of APV into the BLA exhibited no conditional freezing on Test Day 1, suggesting that pretraining infusion of APV in the BLA prevented the acquisition of contextual fear conditioning. Rats that received massed-trial context conditioning in the $\mathrm{B}$ context ( $\mathrm{B}+/ \mathrm{VEH}-\mathrm{BLA}$ group) also did not exhibit conditional freezing on Test Day 1, indicating that freezing in the A+/VEH-BLA group was associative. These impressions were confirmed in the ANOVA by a significant main effect of group, $F(3,65)=10.69, p<.0001$. Post hoc comparisons confirmed that the levels of freezing in the $\mathrm{B}+/ \mathrm{VEH}-\mathrm{BLA}, \mathrm{A}+$ / APV-BLA, and A-/APV-BLA groups were significantly lower than those shown by rats in the $A+/ V E H-B L A$ group. Hence, APV infusion into the BLA prevented the acquisition of associative contextual freezing.

As with Experiment 1, we expressed the percentage of time spent freezing on each day relative to the maximum percentage of time spent freezing to more closely examine the rate of reacquisition of conditional fear. With this measure, it is clear that rats infused with APV in the BLA (Figure 5B) reacquired contextual fear at a rate identical to the rate of naive rats that did not receive any footshock on the initial training day (the A-/VEH-BLA group). Interestingly, rats in the A+/APV-BLA group also reacquired conditional freezing more slowly than rats that received massed-trial fear conditioning in a different context $(\mathrm{B}+/ \mathrm{VEH}-$ BLA group). That is, there was no evidence for savings of fear memory in rats fear conditioned after intra-BLA APV infusions. These results were supported by a significant main effect of group $F(3,65)=8.28, p<.0001$, and a significant Group $\times$ Day interaction, $F(15,325)=4.25, p<.0001$. Also, post hoc comparisons confirmed that rats in the A+/APV-BLA group did not exhibit different freezing levels from rats in the A-/VEH-BLA group on any test day.

As shown in Figure 6A, intra-CEA infusion of APV before massed-trial contextual fear conditioning abolished the acquisition of contextual fear conditioning. This was confirmed in the ANOVA by a significant main effect of group, $F(3,83)=10.04$, 
A

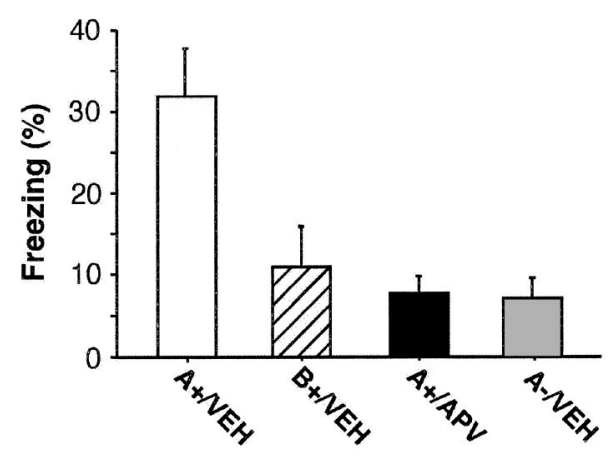

B

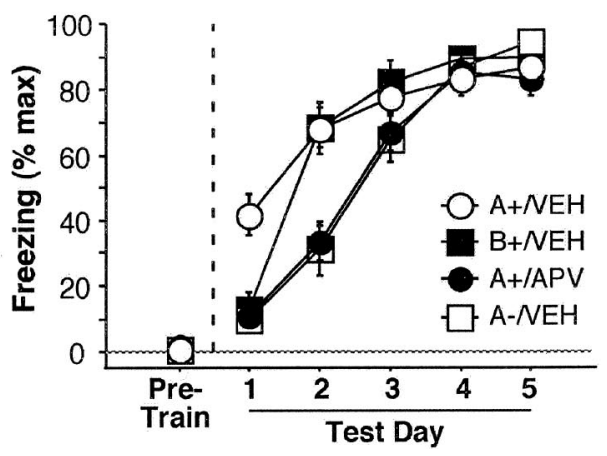

Figure 5. A: Mean $( \pm S E M)$ levels of freezing on the first test day in rats infused with D,L-2-amino-5phosphonovalerate (APV) or vehicle (VEH) in the basolateral complex of the amygdala (BLA) before massedtrial contextual fear conditioning in Experiment 2. B: Conditional freezing to contextual cues before massed-trial training (Pre-Train) and on test days in rats receiving infusions of APV or VEH in the BLA before massed-trial auditory fear conditioning. As was done in Experiment 1, the maximum (max) percentage of time spent freezing over the 5 test days was identified, and the mean $( \pm S E M)$ percentage of time spent freezing on each day was expressed relative to this value for each rat. Conditional freezing was measured during the 3 min before footshock administration on each day. Freezing on any given day reflects the cumulative associative value of the context-unconditional stimulus association from all previous conditioning sessions. Groups differed in terms of the type of infusion (APV or VEH) received immediately before massed-trial training, the context (A or B) in which massed-trial training was administered, and the presence $(+)$ or absence $(-)$ of footshock on the training day.

$p<.0001$. Post hoc comparisons revealed that rats in the $\mathrm{A}+$ / APV-CEA group exhibited levels of freezing on Test Day 1 that were not significantly different from rats in either the $\mathrm{A}-/ \mathrm{VEH}-$ $\mathrm{CEA}$ or $\mathrm{B}+/ \mathrm{VEH}-\mathrm{CEA}$ group. However, rats in the A+/VEHCEA group exhibited significantly higher levels of conditional freezing on Test Day 1 than rats in any other group. Hence, APV infusion into the CEA prevented the acquisition of associative contextual freezing.

In contrast to the pattern of results obtained with intra-BLA infusion of APV, rats infused with APV into the CEA before massed-trial fear conditioning (Figure 6B) showed a faster rate of reacquisition than controls that did not receive massed-trial fear
A

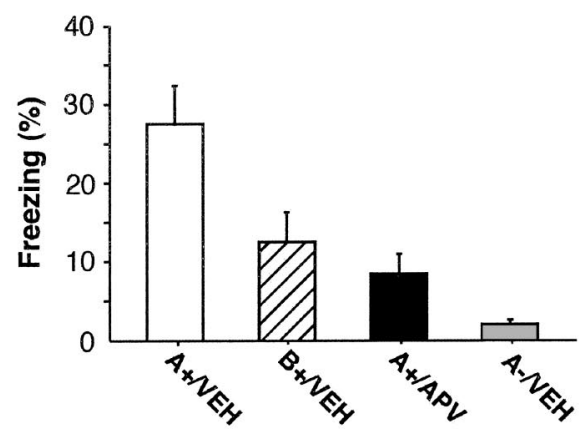

B

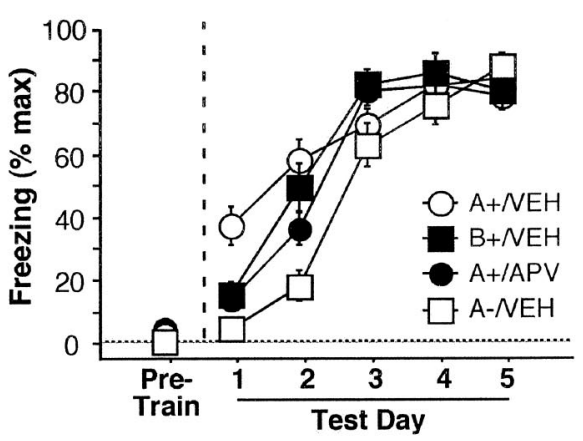

Figure 6. A: Mean ( $\pm S E M)$ levels of freezing on the first test day in rats infused with D,L-2-amino-5phosphonovalerate (APV) or vehicle (VEH) in the central nucleus of the amygdala (CEA) before massed-trial contextual fear conditioning in Experiment 2. B: Conditional freezing to contextual cues before massed-trial training (Pre-Train) and on test days in rats receiving intra-CEA infusions of APV or VEH before massed-trial auditory fear conditioning. For Panel B, the mean ( \pm SEM) percentage of time spent freezing on each day was expressed relative to the maximum (max) percentage of time spent freezing over the 5 test days for each rat. For both Panels A and B, conditional freezing was measured during the 3 min before footshock administration on each test day. Freezing on any given day reflects the cumulative associative value of the context-unconditional stimulus association from all previous conditioning sessions. Groups differed in terms of the type of infusion (APV or VEH) received immediately before massed-trial training, the context (A or B) in which massed-trial training was administered, and the presence $(+)$ or absence $(-)$ of footshock on the training day. 
conditioning. An ANOVA revealed a significant main effect of group, $F(3,83)=7.63, p=.0001$, and a significant Group $\times$ Day interaction, $F(15,415)=3.90, p=.0001$. The rate of reacquisition in the A+/APV-CEA group was equivalent to that of rats receiving massed-trial footshock in a different context $(\mathrm{B}+/ \mathrm{VEH}-$ CEA): Post hoc comparisons confirmed that the levels of conditional freezing expressed by rats in the A+/APV group were equivalent to those expressed by rats in the $\mathrm{B}+/ \mathrm{VEH}$ group at all time points. These data indicate that rats receiving fear conditioning after intra-CEA infusions of APV exhibit some savings of fear memory.

Importantly, the deficits in acquisition of conditional fear that we observed in rats infused with APV were due to local effects of the APV in the amygdala and not to distal effects in adjacent structures. As can be seen in Figure 7, infusion of APV into the $\mathrm{CPu}$ dorsal to the amygdala before massed-trial contextual fear conditioning had no effect on either acquisition or savings of conditional fear. The ANOVA revealed a significant main effect of group, $F(2,78)=15.96, p<.0001$, and a significant Group $\times$ Day interaction, $F(10,390)=7.29, p<.0001$. Post hoc comparisons revealed that rats in the $\mathrm{A}+/ \mathrm{APV}-\mathrm{CPu}$ group did not differ from rats in the $\mathrm{A}+/ \mathrm{VEH}$ group on any test day.

In this study, rats in the A+/VEH-BLA control group exhibited relatively low levels of conditional contextual freezing on Test Day 1 (approximately 30\%), especially in comparison with the levels of conditional tone-elicited freezing observed in comparable control animals in Experiment 1 (approximately 55\%). It could be argued that there was insufficient associative fear after massedtrial fear conditioning to promote savings in the A+/APV-BLA group. To further examine this issue, we assessed the rate of reacquisition of conditional contextual freezing in animals exhibiting the greatest levels of conditional freezing after massed-trial training. The data from the top quartile of animals in each group (based on conditional freezing exhibited on Test Day 1) were

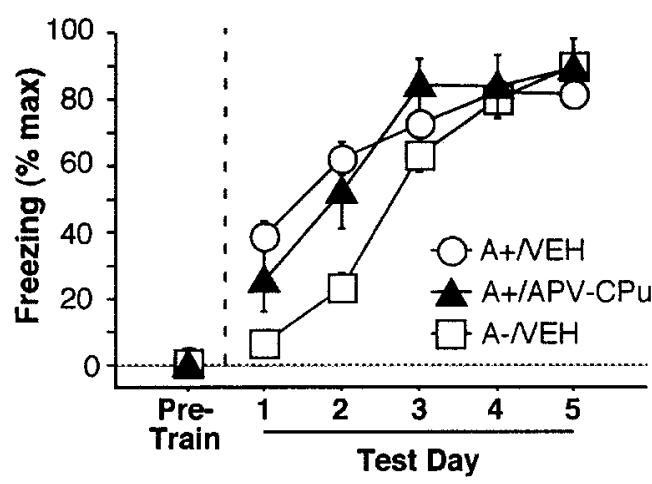

Figure 7. Reacquisition of conditional contextual freezing in rats infused with D,L-2-amino-5-phosphonovalerate (APV) or vehicle (VEH) in the caudate-putamen $(\mathrm{CPu})$ before massed-trial training (Pre-Train) in Experiment 2. Each point represents the mean $( \pm S E M)$ percentage of time spent freezing during a 3-min test period. Groups differed in terms of the type of infusion (APV or VEH) received immediately before massed-trial training, the context (A or B) in which massed-trial training was administered, and the presence $(+)$ or absence $(-)$ of footshock on the training day. Data from rats in the $\mathrm{A}+/ \mathrm{VEH}$ and $\mathrm{A}-/ \mathrm{VEH}$ groups are collapsed across both basolateral complex and central nucleus cannula placements. $\max =$ maximum.

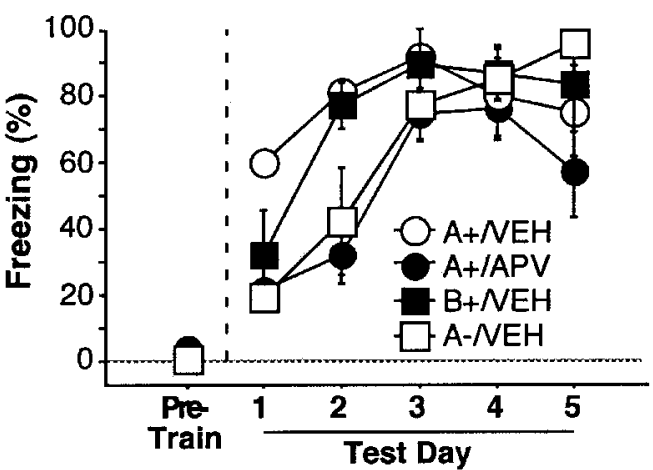

Figure 8. Reacquisition of conditional contextual freezing in rats infused with D,L-2-amino-5-phosphonovalerate (APV) or vehicle (VEH) in the basolateral complex of the amygdala before massed-trial training (PreTrain) in Experiment 2. Only rats exhibiting freezing levels in the top quartile for each group on Test Day 1 were included in the analysis. Each point represents the mean ( $\pm S E M$ ) percentage of time spent freezing during a 3-min test period. Groups differed in terms of the type of infusion (APV or $\mathrm{VEH}$ ) received immediately before massed-trial training, the context (A or B) in which massed-trial training was administered, and the presence $(+)$ or absence $(-)$ of footshock on the training day.

averaged, and these averages are depicted in Figure 8. From these data, it is clear that animals in the A+/VEH-BLA group exhibited high levels of freezing after massed-trial training (roughly 60\%), but animals infused with APV (A+/APV-BLA group) still exhibited no savings of conditional contextual fear. Thus, even at best, animals infused with APV in the BLA do not show savings for their original massed-trial training. These results were confirmed in the ANOVA by a near-significant main effect of group, $F(3$, $13)=3.21, p=.06$, and a significant Group $\times$ Day interaction, $F(15,65)=2.73, p<.01$. Post hoc comparisons showed that rats in the A+/APV-BLA group did not differ from the A-/VEHBLA group through Test Day 4.

Thus, this experiment shows that pretraining infusion of APV in the BLA or CEA produced massive impairments in the acquisition of conditional contextual freezing. These effects were not attributable to diffusion into the overlying $\mathrm{CPu}$. In addition, whereas intra-BLA infusion of APV prevented behavioral savings of context conditioning, animals receiving intra-CEA infusions of APV before training exhibited a level of savings comparable to that exhibited by rats that received footshock in a different context on the massed-trial training day ( $\mathrm{B}+/ \mathrm{VEH}-\mathrm{CEA}$ group).

\section{General Discussion}

The present results suggest that NMDA receptor activation in both the BLA and CEA is essential for the acquisition of Pavlovian fear conditioning. These experiments reveal that infusion of APV into the BLA or CEA before fear conditioning prevents the acquisition of auditory and contextual conditional fear. These experiments also reveal behavioral savings of conditional contextual and auditory fear, as measured by the rate of reacquisition during subsequent drug-free retraining, in rats infused with APV into the CEA, but not BLA, before fear conditioning. This confirms and extends the results of numerous experiments indicating that APV infusion into the BLA blocks the acquisition of conditional freez- 
ing (H. Lee \& Kim, 1998; Maren, Aharonov, et al., 1996). Moreover, our results suggest that functional NMDA receptors in both the BLA and CEA are needed to acquire conditional fear responses. The deficits in associative fear memory observed after intra-amygdala infusion of APV are not due to diffusion to nearby structures, such as the $\mathrm{CPu}$ (Experiment 2), or diffusion of APV between the CEA and BLA. Indeed, we have previously obtained dissociations in behavior after infusing drugs into the BLA and CEA using the stereotaxic coordinates and infusion volumes reported here (Goosens, Holt, \& Maren, 2000). The present results therefore reveal a novel role for NMDA receptors in the CEA in the acquisition of Pavlovian fear conditioning.

Our results complement and extend those of previous studies examining savings of Pavlovian conditional fear after BLA manipulations. For example, our laboratory has previously shown that even extensive overtraining does not yield savings of conditional fear in rats with posttraining BLA lesions (Maren, 1998, 1999b, 2001a). We have also shown that pretraining inactivation of the BLA with the gamma-aminobutyric-acid $\left(\mathrm{GABA}_{\mathrm{A}}\right)$ receptor agonist muscimol prevents behavioral savings of conditional auditory fear (Maren et al., 2001). Moreover, although one report has suggested that rats with large neurotoxic lesions of the BLA exhibit savings of contextual fear (Cahill, Vazdarjanova, \& Setlow, 2000), the behavior of these rats was not compared with the behavior of unshocked controls. Our laboratory has done an extensive comparison of the freezing behavior exhibited by rats with large neurotoxic BLA lesions with the freezing exhibited by unshocked control rats, and no difference (i.e., no savings) was observed in the lesioned rats across any measure (Maren, 2001a).

In Experiment 2, we observed that the level of savings of rats in the A+/APV-CEA group was comparable to the savings exhibited by VEH-infused rats that received footshock exposure in a different context on the massed-trial training day $(\mathrm{B}+/ \mathrm{VEH}-\mathrm{CEA})$. The savings exhibited by rats in the $\mathrm{B}+/ \mathrm{VEH}-\mathrm{CEA}$ group may reflect associative generalization between the training and testing contexts. Alternatively, these savings may be attributable to a nonassociative stress-related facilitation of learning similar to the facilitation of the acquisition of eyeblink conditioning by tailshock stress (Shors \& Mathew, 1998). Likewise, the savings observed after intra-CEA infusion of APV may be either associative or nonassociative. With regard to the former, a small portion of the CEA may have remained functional during massed-trial training. Functional CEA neurons may have acquired a subthreshold associative memory trace that produced behavioral savings with additional training. It is also possible that nonassociative effects of footshock stress during massed-trial training enhanced the subsequent acquisition of conditional fear with further training in a different context. The latter explanation is particularly appealing, in that nonassociative facilitation of learning by shock stress is mediated by the BLA and not the CEA (Shors \& Mathew, 1998).

Consistent with these findings, we have observed facilitated learning (i.e., savings) of conditional fear after infusion of APV in the CEA but not the BLA. Thus, our data suggest that the BLA may be capable of processing some aspects of the footshock US in the absence of a functional CEA but that this spared memory is not apparent without additional fear conditioning. In this case, our data further indicate that NMDA receptor blockade in the BLA prevents both associative and nonassociative processing during fear conditioning. In contrast, NMDA receptor blockade in the CEA interfered only with associative processing.

The findings reported here agree with a number of studies highlighting the importance of the amygdala in acquisition of Pavlovian conditional fear. For example, two recent studies have shown that much of the plasticity observed in the MGN after fear conditioning is amygdala dependent (Maren et al., 2001; Poremba $\&$ Gabriel, 2001). Thus, in the absence of the amygdala, at least one amygdala afferent is unable to acquire long-term associative plasticity. Our data suggest that, in the absence of functional amygdaloid NMDA receptors, other amygdala afferents may be similarly impaired in the acquisition of long-term plasticity, or the plasticity acquired is simply insufficient to drive conditional responding.

A recent model of the cellular mechanisms in the amygdala that underlie associative fear learning (Blair, Schafe, Bauer, Rodrigues, \& LeDoux, 2001) suggests that NMDA receptors play a critical role in initiating long-term synaptic plasticity in amygdala neurons. By this model, ionic currents flowing through non-NMDA receptors yield back-propagating action potentials that activate dendritic voltage-gated calcium channels (VGCCs). VGCCs convert the short-term plasticity enabled by the NMDA receptor to a more enduring form of long-term synaptic plasticity (i.e., longterm potentiation). This model predicts that NMDA receptor antagonism in the BLA during fear conditioning would prevent both short- and long-term synaptic plasticity. Our results support this model and suggest that NMDA receptor-dependent synaptic plasticity is critical for establishing long-term fear memories. Of course, NMDA receptor antagonists may have impaired memory by reducing the excitability of amygdaloid neurons, independent of any effects on synaptic plasticity (Fendt, 2001; H. J. Lee et al., 2001; Maren, Aharonov, et al., 1996; Maren \& Fanselow, 1995).

Our data are not consistent with the suggestion that physiological plasticity observed in the BLA and CEA during aversive associative learning (e.g., Maren, 2000; Quirk et al., 1995, 1997) is passively mirrored from afferent structures (Weinberger et al., 1993). Similarly, our data are not consistent with claims that the amygdala serves only to modulate Pavlovian associative memories generated and stored elsewhere (McGaugh, Introini-Collison, Cahill, Kim, \& Liang, 1992). In both of these cases, extra-amygdaloid structures would be expected to mediate associative learning during fear conditioning under NMDA receptor blockade of the amygdala. The deficits in conditional fear observed in animals trained under amygdaloid NMDA receptor antagonism could then be attributed to either a retrieval failure during extinction testing or the failure of the original training to generate a strong memory trace. However, when additional training is administered, one would predict that rats trained under NMDA receptor blockade of the BLA or CEA should reacquire conditional fear at a rate faster than that of nonshocked controls, demonstrating savings of conditional fear. This pattern of results has been observed in the eyeblink-conditioning paradigm, for example (Clark \& Lavond, 1993; Krupa, Thompson, \& Thompson, 1993). In this case, inactivation of the cerebellum, the locus of CS-US association, prevented acquisition of eyeblink conditioning and resulted in no savings for the original training. In contrast, inactivation of the red nucleus, a performance structure that translates the CS-US association into the eyeblink conditional response, resulted in substantial savings for the original training. The results presented here 
indicate that there is no savings of contextual fear or auditory fear after training under NMDA receptor blockade in the BLA. This suggests that the BLA is a critical locus of plasticity during Pavlovian fear conditioning.

Our results are also inconsistent with one study suggesting that infusion of APV in the CEA has no effect on acquisition of Pavlovian fear conditioning (Fanselow \& Kim, 1994). The reason for this discrepancy is unclear; however, a more anterior portion of the CEA was targeted in the present experiments. This may have resulted in inactivation of a larger portion of the medial division of the CEA (CEAm) by APV infusion than in the study by Fanselow and colleagues. Because the CEAm is the portion of the central nucleus that projects most heavily to the brain areas responsible for driving conditional responding (LeDoux et al., 1988; Veening, Swanson, \& Sawchenko, 1984), the coordinates used in the present experiments may have inactivated the portion of the CEA that plays the most critical role in fear conditioning.

Several studies have reported that lesions of the CEA affect the acquisition of Pavlovian appetitive tasks (Gallagher, Graham, \& Holland, 1990; Parkinson, Robbins, \& Everitt, 2000). Thus, it is clear that the CEA plays a critical role in associative learning in at least some Pavlovian paradigms. In spite of the role the CEA plays in the acquisition of other Pavlovian conditional responses, the nature of the role of the CEA in Pavlovian fear conditioning has remained elusive. It is often assumed that the largely unidirectional transmission of information that leads to a rather strict segregation of learning and performance structures in the circuitry underlying eyeblink conditioning (Clark \& Lavond, 1993; Krupa et al., 1993; Medina, Repa, Mauk, \& LeDoux, 2002; Steinmetz, 2000) exists as well in the circuitry supporting fear conditioning (LeDoux, 2000; Maren, 2001b). Also, the CEA is ideally situated to be a performance structure because it directly projects to the brainstem nuclei that control the conditional responses evoked by fearful stimuli (LeDoux et al., 1988). Yet, it has since been shown that there is extensive reciprocal information flow between amygdaloid nuclei (Pitkänen, Savander, \& LeDoux, 1997). Thus, a strict segregation of learning and performance may not be applicable to fear conditioning circuitry. Indeed, because the CEA itself is a site of CS-US convergence, it seems likely that plasticity in the CEA is involved in the acquisition of fear conditioning (see Pascoe, Supple, \& Kapp, 1991).

In support of this, there are recent reports that manipulations of CEA block the acquisition of conditional freezing. Specifically, acquisition of Pavlovian fear conditioning can be blocked by pretraining inactivation of CEA with muscimol, and this effect can be observed with smaller doses of muscimol than those required with intra-BLA infusions of muscimol (Wilensky, Schafe, \& LeDoux, 2000). Similar to the data reported here, this report suggests that muscimol is interfering with the acquisition of conditional fear through local mechanisms in the CEA, rather than by diffusing to the proximal BLA. Furthermore, it has also been shown that posttraining infusion of the protein synthesis inhibitor anisomycin in the CEA blocks the formation of long-term fear memories (Wilensky, Schafe, \& LeDoux, 2001), paralleling the results obtained with intra-BLA infusion of anisomycin (Schafe \& LeDoux, 2000).

Our observation that NMDA receptor activation in the CEA appears to be critical for the acquisition of conditional fear suggests that the CEA could be a locus of CS-US association under- lying the acquisition of conditional freezing (Pascoe \& Kapp, 1985). Whereas this is consistent with reports showing associative plasticity in CEA after fear learning, we have recently shown that intra-amygdala infusion of a protein kinase $\mathrm{A}$ and $\mathrm{C}$ inhibitor blocks the acquisition of conditional fear when infused into the BLA but not the CEA (Goosens et al., 2000). This suggests that if the BLA and CEA both play roles in the long-term storage of the associative plasticity underlying fear conditioning, they must do so by different molecular mechanisms. Alternatively, the CEA might have NMDA-receptor-dependent projections that tonically modulate activity in the BLA. Because APV has been shown to block synaptic transmission in the BLA (Maren \& Fanselow, 1995), intra-CEA administration of APV might also inactivate CEA neurons and indirectly disrupt synaptic transmission in the BLA. In this case, the disruption of Pavlovian fear conditioning observed after intra-CEA infusion of APV would occur through indirect mechanisms. Further research will be aimed at distinguishing between these hypotheses and clarifying the role of the CEA in Pavlovian fear conditioning.

\section{References}

Applegate, C. D., Frysinger, R. C., Kapp, B. S., \& Gallagher, M. (1982). Multiple unit activity recorded from amygdala central nucleus during Pavlovian heart rate conditioning in rabbit. Brain Research, 238, 457462

Blair, H. T., Schafe, G. E., Bauer, E. P., Rodrigues, S. M., \& LeDoux, J. E. (2001). Synaptic plasticity in the lateral amygdala: A cellular hypothesis of fear conditioning. Learning and Memory, 8, 229-242.

Cahill, L., Vazdarjanova, A., \& Setlow, B. (2000). The basolateral amygdala complex is involved with, but is not necessary for, rapid acquisition of Pavlovian fear conditioning. European Journal of Neuroscience, 12, 3044-3050.

Cahill, L., Weinberger, N. M., Roozendaal, B., \& McGaugh, J. L. (1999). Is the amygdala a locus of "conditioned fear"? Some questions and caveats. Neuron, 23, 227-228.

Campeau, S., \& Davis, M. (1995). Involvement of the central nucleus and basolateral complex of the amygdala in fear conditioning measured with fear-potentiated startle in rats trained concurrently with auditory and visual conditioned stimuli. Journal of Neuroscience, 15, 2301-2311.

Campeau, S., Miserendino, M. J., \& Davis, M. (1992). Intra-amygdala infusion of the N-methyl-D-aspartate receptor antagonist AP5 blocks acquisition but not expression of fear-potentiated startle to an auditory conditioned stimulus. Behavioral Neuroscience, 106, 569-574.

Canteras, N. S., \& Swanson, L. W. (1992). Projections of the ventral subiculum to the amygdala, septum, and hypothalamus: A PHAL anterograde tract-tracing study in the rat. Journal of Comparative Neurology, 324, 180-194.

Clark, R. E., \& Lavond, D. G. (1993). Reversible lesions of the red nucleus during acquisition and retention of a classically conditioned behavior in rabbits. Behavioral Neuroscience, 107, 264-270.

Clugnet, M. C., \& LeDoux, J. E. (1990). Synaptic plasticity in fear conditioning circuits: Induction of LTP in the lateral nucleus of the amygdala by stimulation of the medial geniculate body. Journal of Neuroscience, 10, 2818-2924.

Davis, M. (1992). The role of the amygdala in fear and anxiety. Annual Review of Neuroscience, 15, 353-375.

De Oca, B. M., DeCola, J. P., Maren, S., \& Fanselow, M. S. (1998) Distinct regions of the periaqueductal gray are involved in the acquisition and expression of defensive responses. Journal of Neuroscience, 18 , 3426-3432.

Edeline, J. M., \& Weinberger, N. M. (1992). Associative retuning in the thalamic source of input to the amygdala and auditory cortex: Receptive 
field plasticity in the medial division of the medial geniculate body. Behavioral Neuroscience, 106, 81-105.

Fanselow, M. S., \& Kim, J. J. (1994). Acquisition of contextual Pavlovian fear conditioning is blocked by application of an NMDA receptor antagonist D,L-2-amino-5-phosphonovaleric acid to the basolateral amygdala. Behavioral Neuroscience, 108, 210-212.

Fanselow, M. S., \& LeDoux, J. E. (1999). Why we think plasticity underlying Pavlovian fear conditioning occurs in the basolateral amygdala. Neuron, 23, 229-232.

Fendt, M. (2001). Injections of the NMDA receptor antagonist aminophosphonopentanoic acid into the lateral nucleus of the amygdala block the expression of fear-potentiated startle and freezing. Journal of Neuroscience, 21, 4111-4115.

Fendt, M., \& Fanselow, M. S. (1999). The neuroanatomical and neurochemical basis of conditioned fear. Neuroscience and Biobehavioral Reviews, 23, 743-760.

Gallagher, M., Graham, P. W., \& Holland, P. C. (1990). The amygdala central nucleus and appetitive Pavlovian conditioning: Lesions impair one class of conditioned behavior. Journal of Neuroscience, 10, 19061911.

Gerren, R. A., \& Weinberger, N. M. (1983). Long term potentiation in the magnocellular medial geniculate nucleus of the anesthetized cat. Brain Research, 265, 138-142.

Gewirtz, J. C., \& Davis, M. (1997). Second-order fear conditioning prevented by blocking NMDA receptors in amygdala. Nature, 388, 471474.

Goosens, K. A., Holt, W., \& Maren, S. (2000). A role for amygdaloid PKA and $\mathrm{PKC}$ in the acquisition of long-term conditional fear memories in rats. Behavioural Brain Research, 114, 145-152.

Goosens, K. A., \& Maren, S. (2001). Contextual and auditory fear conditioning are mediated by the lateral, basal, and central amygdaloid nuclei in rats. Learning and Memory, 8, 148-155.

Kim, J. J., \& Fanselow, M. S. (1992). Modality-specific retrograde amnesia of fear. Science, 256, 675-677.

Kim, J. J., Rison, R. A., \& Fanselow, M. S. (1993). Effects of amygdala, hippocampus, and periaqueductal gray lesions on short- and long-term contextual fear. Behavioral Neuroscience, 107, 1093-1098.

Krupa, D. J., Thompson, J. K., \& Thompson, R. F. (1993). Localization of a memory trace in the mammalian brain. Science, 260, 989-991.

LeDoux, J. E. (2000). Emotion circuits in the brain. Annual Review of Neuroscience, 23, 155-184.

LeDoux, J. E., Farb, C. R., \& Romanski, L. M. (1991). Overlapping projections to the amygdala and striatum from auditory processing areas of the thalamus and cortex. Neuroscience Letters, 134, 139-144.

LeDoux, J. E., Iwata, J., Cicchetti, P., \& Reis, D. J. (1988). Different projections of the central amygdaloid nucleus mediate autonomic and behavioral correlates of conditioned fear. Journal of Neuroscience, 8 , 2517-2529.

Lee, H. J., Choi, J. S., Brown, T. H., \& Kim, J. J. (2001). Amygdalar NMDA receptors are critical for the expression of multiple conditioned fear responses. Journal of Neuroscience, 21, 4116-4124.

Lee, H., \& Kim, J. J. (1998). Amygdalar NMDA receptors are critical for new fear learning in previously fear-conditioned rats. Journal of Neuroscience, 18, 8444-8454.

Lee, Y., Walker, D., \& Davis, M. (1996). Lack of a temporal gradient of retrograde amnesia following NMDA-induced lesions of the basolateral amygdala assessed with the fear-potentiated startle paradigm. Behavioral Neuroscience, 110, 836-839.

Lennartz, R. C., \& Weinberger, N. M. (1992). Frequency-specific receptive field plasticity in the medial geniculate body induced by Pavlovian fear conditioning is expressed in the anesthetized brain. Behavioral Neuroscience, 106, 484-497.

Maren, S. (1998). Overtraining does not mitigate contextual fear condi- tioning deficits produced by neurotoxic lesions of the basolateral amygdala. Journal of Neuroscience, 18, 3088-3097.

Maren, S. (1999a). Long-term potentiation in the amygdala: A mechanism for emotional learning and memory. Trends in Neuroscience, 22, 561567.

Maren, S. (1999b). Neurotoxic basolateral amygdala lesions impair learning and memory but not the performance of conditional fear in rats. Journal of Neuroscience, 19, 8696-8703.

Maren, S. (2000). Auditory fear conditioning increases CS-elicited spike firing in lateral amygdala neurons even after extensive overtraining. European Journal of Neuroscience, 12, 4047-4054.

Maren, S. (2001a). Is there savings for Pavlovian fear conditioning after neurotoxic basolateral amygdala lesions in rats? Neurobiology of Learning and Memory, 76, 268-283.

Maren, S. (2001b). Neurobiology of Pavlovian fear conditioning. Annual Review of Neuroscience, 24, 897-931.

Maren, S., Aharonov, G., \& Fanselow, M. S. (1996). Retrograde abolition of conditional fear after excitotoxic lesions in the basolateral amygdala of rats: Absence of a temporal gradient. Behavioral Neuroscience, 110 , $718-726$.

Maren, S., Aharonov, G., \& Fanselow, M. S. (1997). Neurotoxic lesions of the dorsal hippocampus and Pavlovian fear conditioning in rats. Behavioural Brain Research, 88, 261-274.

Maren, S., Aharonov, G., Stote, D. L., \& Fanselow, M. S. (1996). $\mathrm{N}$-methyl-D-aspartate receptors in the basolateral amygdala are required for both acquisition and expression of conditional fear in rats. Behavioral Neuroscience, 110, 1365-1374

Maren, S., \& Fanselow, M. S. (1995). Synaptic plasticity in the basolateral amygdala induced by hippocampal formation stimulation in vivo. Journal of Neuroscience, 15, 7548-7564.

Maren, S., \& Fanselow, M. S. (1996). The amygdala and fear conditioning: Has the nut been cracked? Neuron, 16, 237-240.

Maren, S., Poremba, A., \& Gabriel, M. (1991). Basolateral amygdaloid multi-unit neuronal correlates of discriminative avoidance learning in rabbits. Brain Research, 549, 311-316.

Maren, S., Yap, S. A., \& Goosens, K. A. (2001). The amygdala is essential for the development of neuronal plasticity in the medial geniculate nucleus during auditory fear conditioning in rats. Journal of Neuroscience, 21, RC135.

McEchron, M. D., Green, E. J., Winters, R. W., Nolen, T. G., Schneiderman, N., \& McCabe, P. M. (1996). Changes of synaptic efficacy in the medial geniculate nucleus as a result of auditory classical conditioning. Journal of Neuroscience, 16, 1273-1283.

McEchron, M. D., McCabe, P. M., Green, E. J., Llabre, M. M., \& Schneiderman, N. (1995). Simultaneous single unit recording in the medial nucleus of the medial geniculate nucleus and amygdaloid central nucleus throughout habituation, acquisition, and extinction of the rabbit's classically conditioned heart rate. Brain Research, 682, 157-166.

McGaugh, J. L., Introini-Collison, I. B., Cahill, L., Kim, M., \& Liang, K. C. (1992). Involvement of the amygdala in neuromodulatory influences on memory storage. In J. P. Aggleton (Ed.), The amygdala: Neurobiological aspects of emotion, memory, and mental dysfunction (pp. 1-66). New York: Wiley-Liss.

McKernan, M. G., \& Shinnick-Gallagher, P. (1997). Fear conditioning induces a lasting potentiation of synaptic currents in vitro. Nature, 390, $607-611$.

Medina, J. F., Repa, J. C., Mauk, M. D., \& LeDoux, J. E. (2002). Parallels between cerebellum- and amygdala-dependent conditioning. Nature Reviews Neuroscience, 3, 122-131.

Miserendino, M. J., Sananes, C. B., Melia, K. R., \& Davis, M. (1990, June 21). Blocking of acquisition but not expression of conditioned fearpotentiated startle by NMDA antagonists in the amygdala. Nature, 345, $716-718$.

Parkinson, J. A., Robbins, T. W., \& Everitt, B. J. (2000). Dissociable roles 
of the central and basolateral amygdala in appetitive emotional learning. European Journal of Neuroscience, 12, 405-413.

Pascoe, J. P., \& Kapp, B. S. (1985). Electrophysiological characteristics of amygdaloid central nucleus neurons during Pavlovian fear conditioning in the rabbit. Behavioural Brain Research, 16, 117-133.

Pascoe, J. P., Supple, W. F., \& Kapp, B. S. (1991). Learning and memory: Vertebrate models. In J. L. Martinez \& R. P. Kesner (Eds.), Learning and memory: A biological view (pp. 359-407). San Diego, CA: Academic Press.

Phillips, R. G., \& LeDoux, J. E. (1992). Differential contribution of amygdala and hippocampus to cued and contextual fear conditioning. Behavioral Neuroscience, 106, 274-285.

Pitkänen, A., Savander, V., \& LeDoux, J. E. (1997). Organization of intra-amygdaloid circuitries in the rat: An emerging framework for understanding functions of the amygdala. Trends in Neuroscience, 20, 517-523.

Poremba, A., \& Gabriel, M. (2001). Amygdalar efferents initiate auditory thalamic discriminative training-induced neuronal activity. Journal of Neuroscience, 21, 270-278.

Quirk, G. J., Armony, J. L., \& LeDoux, J. E. (1997). Fear conditioning enhances different temporal components of tone-evoked spike trains in auditory cortex and lateral amygdala. Neuron, 19, 613-624.

Quirk, G. J., Repa, J. C., \& LeDoux, J. E. (1995). Fear conditioning enhances short-latency auditory responses of lateral amygdala neurons: Parallel recordings in the freely behaving rat. Neuron, 15, 1029-1039.

Repa, J. C., Apergis, J., Desrochers, T. M., Zhou, Y., \& LeDoux, J. E. (2001). Two different lateral amygdala cell populations contribute to the initiation and storage of memory. Nature Neuroscience, 4, 724-731.

Rogan, M. T., \& LeDoux, J. E. (1995). LTP is accompanied by commensurate enhancement of auditory-evoked responses in a fear conditioning circuit. Neuron, 15, 127-136.

Rogan, M. T., Staübli, U. V., \& LeDoux, J. E. (1997). Fear conditioning induces associative long-term potentiation in the amygdala. Nature, 390, 604-607.

Romanski, L. M., \& LeDoux, J. E. (1992). Equipotentiality of thalamo- amygdala and thalamo-cortico-amygdala circuits in auditory fear conditioning. Journal of Neuroscience, 12, 4501-4509.

Sananes, C. B., \& Davis, M. (1992). N-methyl-D-aspartate lesions of the lateral and basolateral nuclei of the amygdala block fear-potentiated startle and shock sensitization of startle. Behavioral Neuroscience, 106, $72-80$.

Schafe, G. E., \& LeDoux, J. E. (2000). Memory consolidation of auditory Pavlovian fear conditioning requires protein synthesis and protein kinase A in the amygdala. Journal of Neuroscience, 20, RC96.

Shors, T. J., \& Mathew, P. R. (1998). NMDA receptor antagonism in the lateral/basolateral but not central nucleus of the amygdala prevents the induction of facilitated learning in response to stress. Learning and Memory, 5, 220-230.

Steinmetz, J. (2000). Brain substrates of classical eyeblink conditioning: A highly localized but also distributed system. Behavioural Brain Research, 110, 13-24.

Swanson, L. W. (1999). Brain maps: Structure of the rat brain (2nd ed.). Amsterdam: Elsevier.

Veening, J. G., Swanson, L. W., \& Sawchenko, P. E. (1984). The organization of projections from the central nucleus of the amygdala to brainstem sites involved in central autonomic regulation: A combined retrograde transport-immunohistochemical study. Brain Research, 303, 337-357.

Weinberger, N. M., Javid, R., \& Lepan, B. (1993). Long-term retention of learning-induced receptive-field plasticity in the auditory cortex. Proceedings of the National Academy of Sciences, USA, 90, 2394-2398.

Wilensky, A. E., Schafe, G. E., \& LeDoux, J. E. (2000). Functional inactivation of amygdale nuclei during acquisition of Pavlovian fear conditioning. Society for Neuroscience Abstracts, 26, 465.

Wilensky, A. E., Schafe, G. E., \& LeDoux, J. E. (2001). Does the central nucleus of the amygdale contribute to the consolidation of auditory fear conditioning? Society for Neuroscience Abstracts, 27, 187.

Received July 22, 2002

Revision received March 5, 2003

Accepted March 7, 2003

\section{Wanted: Your Old Issues!}

As APA continues its efforts to digitize journal issues for the PsycARTICLES database, we are finding that older issues are increasingly unavailable in our inventory. We are turning to our long-time subscribers for assistance. If you would like to donate any back issues toward this effort (preceding 1982), please get in touch with us at journals@apa.org and specify the journal titles, volumes, and issue numbers that you would like us to take off your hands. 